\title{
Haematological and Serum Biochemical Responses of Ovambo Chickens Fed Provitamin A Biofortified Maize
}

\section{-Author(s)}

\section{Odunitan-Wayas $\mathrm{F}^{\prime}$}

Kolanisi U'

Chimonyo $\mathrm{M}^{\prime}$

University of KwaZulu-Natal, Pietermaritzburg Campus School of Agricultural Earth and Environmental Sciences, Private Bag X01, Scottsville, 3209, South Africa.

\section{-Mail Address}

Corresponding author e-mail address Michael Chimonyo

Department of Animal and Poultry Science, School of Agricultural, Earth and Environmental Sciences, University of KwaZulu- Natal,Private Bag X01, Scottsville, 3209, South Africa. Phone: +27767309002

Email: chimonyo@ukzn.ac.za

\section{aKeywords}

Blood profiles, health assessment, indigenous chicken, provitamin A biofortified maize diet.

\section{ABSTRACT}

The current study was conducted to investigate the influence of provitamin A biofortified maize (PABM) diet, sex and age of birds on the haematological and serum biochemistry parameters of indigenous chickens. A total of ninety-six 13 week old male and female Ovambo chickens were reared and fed on either white maize (WM) a low vitamin A diet or a PABM based diet for eight weeks. Each diet was replicated four times. Packed cell volume $(\mathrm{PCV})$, haemoglobin $(\mathrm{Hb})$, erythrocyte concentration (RBC), leucocytes concentration (WBC), mean corpuscular volume (MCV), mean corpuscular haemoglobin (MCH) and mean corpuscular haemoglobin concentration (MCHC) were measured. Albumin (ALB), globulin (GLOB), total proteins (TP), triglycerides (TRI), cholesterol (CHOLES), uric acid (UA) and creatinine (CREAT) concentrations were assessed. The activity of alanine transaminase (ALT) alkaline phosphate (ALP) and aspartate transaminanse (AST) were also assayed. The PABM diet increased $(p<0.05)$ PCV and WBC of female birds. All mean values for the haematological parameters regardless of the age, sex and diets were within the normal range. Age had an effect $(p<0.05)$ on ALT, TP, GLOB, TRI and UA. Sex of the birds significantly influenced the TP, GLOB, ALB, CREAT and TRI levels. There was significant interaction of diet and age of bird on ALP, ALT, and GLOB concentrations. The cholesterol level in 18 weeks old male birds fed on the WM diet was above the normal range. In conclusion, feeding PABM diet to female and male indigenous chickens will not negatively impact on the health status of indigenous chickens.

\section{INTRODUCTION}

Indigenous chickens in Africa are increasingly being preferred for consumption by consumers due to their unique organoleptic properties such as taste, flavour, darker cooked meat colour, chewy texture and low chemical contamination when compared to commercial chickens (Chumngoen \& Tan, 2015; Magala et al., 2012). Diseases and scarcity of nutritious feed are however, some of the major limiting factors of indigenous chicken development and production (Desta \& Wakeyo, 2013). As the growth rate of indigenous chickens is low and feeds are costly, there is minimal need to feed them with high levels of proteins and energy to boost their growth rate and performance as the commercial birds. However, it is important to derive means of improving the general well-being and immune response of indigenous chickens for better development which will improve production without unnecessary higher cost implication.

Vitamin $A$ is a micro-nutrient that is required for immunity, vision, growth and development (Bárdos et al., 2011). It can either be in the form of preformed vitamin A or provitamin A carotenoid. Provitamin A carotenoids have the ability to convert to vitamin A when ingested 
(Pixley et al., 2013). They do not have the risk of vitamin A toxicity as the preformed vitamin A because the cleavage of provitamin A carotenoids to retinal which is converted to retinol is a highly regulated step that is dependent on the body's requirement (Penniston \& Tanumihardjo, 2006). Because of the functions of vitamin A, vitamin A supplement is included in commercial poultry's diet (Desta \& Wakeyo, 2013). Vitamin A supplement $s$ are however not included in the diet of indigenous chickens. Most of the diet of indigenous chickens are got from scavenging and supplementary feed which constitute mainly leftovers from households, whole or crushed maize grains, millets and sorghum (Desta \& Wakeyo, 2013). It is important to include vitamin $A$ in the diet of indigenous chickens because of its functions.

Maize as a major ingredient in the diet of poultry accounts for up to $70 \%$ of their diets (Summers, 2001). The common types of maize used to feed chickens are the white and yellow maize, both low in vitamin A (Aganga et al., 2003; Pillay et al., 2011).White maize is the commonly grown maize for consumption in southern Africa, and indigenous chickens are often given this maize either as whole grain or crushed (Smale et al., 2013). Provitamin A biofortified maize (PABM) has been biofortified with high provitamin A carotenoids, especially $\beta$ - carotene. The PABM has all the nutrients present in yellow and white maize, plus the added benefits of having higher provitamin A carotenoids concentration and the potential of being drought tolerant (Aluru et al., 2008; Liu et al., 2015). The PABM can be easily incorporated into the diet of chickens as it can substitute white maize or yellow maize. It can also be included in their diet in any quantity without any risk of vitamin A toxicity implications. The replacement of white maize by PABM has been established to improve the skin and meat muscle colour of the indigenous chicken with age and sex as contributory factors (Odunitan-Wayas et al., 2016). Skin and meat colour are physically used to assess the freshness, quality and health status of chickens (Kennedy et al., 2005). Haematological and serum biochemical responses are used to assess the clinical and physiological responsiveness and well-being of chickens (Sharma et al., 2015). There are however little or no information on the effect of PABM on the blood composition of the chickens. The replacement of white maize with PABM is likely to boost the immunity and health status of chickens based on the functions of vitamin A. To validate these assumptions, it is important to assess the influence of PABM on the blood composition of the indigenous chickens to determine the extent of its influence on boosting their immunity and health status which will consequently influence their growth and development.

One of the common indigenous chicken breeds in southern Africa is the Ovambo (Van Marle-Koster \& $\mathrm{Nel}, 2000)$. The Ovambo is aggressive and agile and has mostly dark red, brown and black plumage which aids to camouflage the bird to avoid predators, making it popular for rearing among rural poultry farmers (Van Marle-Köster \& Casey, 2001).Ovambo chickens have the highest dressed carcass mass among the South African indigenous breeds (Van Marle-Koster \& Webb, 2000). These superiorities make the Ovambo breed highly desirable for meat purpose. Due to the increasing consumer's demand of the indigenous chicken despite their slow growth and high mortality rates, it is necessary to improve their production for better survival and performance. This will also consequently contribute to the livelihood of the rural poor who rear indigenous chickens. The health status of chickens is paramount in the performance of chickens (Yang et al., 2009). Haematological and serum biochemical parameters are influenced by feed, medication, toxic compounds, infections, age and sex of the birds (dos Santos Schmidt et al., 2009; Huff et al., 2008). The intention of the study was to test whether provitamin A carotenoids in PABM could have an effect on the indigenous chicken's metabolism due to its functions. The objective of the study was to compare the haematological and biochemical responses of female and male Ovambo chickens to PABM at different ages. The hypothesis is that provitamin A biofortified maize, age and sex of the Ovambo chickens have no effect on their blood composition.

\section{MATERIALS AND METHODS}

\section{Study site and the ethical aspects of the study}

The management and care of the chickens were in accordance with internationally accepted standards for the welfare and ethics of chickens. Management and use adopted for the study was approved by the University of KwaZulu-Natal Animal Ethics Research Committee (019/14/Animal). The study was conducted between September 2014 and February 2015 at Cedarain KwaZulu-Natal, South Africa. The site is in the upland savannah zone on $29.53^{\circ} \mathrm{S}$ and $30.27^{\circ} \mathrm{E}$. The average environmental temperature was $21.3^{\circ} \mathrm{C}$ and the relative humidity an average of $63.2 \%$. 
Odunitan-Wayas F, Kolanisi U, Chimonyo M
Haematological and Serum Biochemical Responses of Ovambo Chickens Fed Provitamin A Biofortified Maize

\section{Birds, diets, diet analysis and management}

A total of 200 unsexed Ovambo chicks that were hatched from parent stock by the Agricultural Research Council (ARC), Irene, Pretoria in South Africa were raised together in a well-ventilated floor area of $2 \mathrm{~m}$ by $2.5 \mathrm{~m}$ in width and breadth respectively under a deep litter management system. The floor was adequately covered with $12 \mathrm{~cm}$ layer of wood shavings. A commercial standard broiler starter meal was given ad libitum to the chickens from day 1 to day 49 and commercial standard grower diet was given from day 50 to day 84. Water was offered ad libitum in $4 \mathrm{~L}$ plastic founts and feed was provided in tube feeders made of standard gutter materials. Light and heat were provided continuously using infra-red lamps. The birds were vaccinated against Newcastle disease at 14 days of age. Gumboro vaccine was also given at 6 weeks of age. The vaccinations were administered orally in the drinking water of the chickens.

At 12 weeks (84 days), 48 male (average body weight $=1.5 \pm 0.3 \mathrm{~kg}$ ) and 48 female birds (average body weight $=1.1 \pm 0.4 \mathrm{~kg}$ ) were selected. The birds were acclimatized to their experimental pen environment for 7 days prior to the commencement of the experimental trial at 13 weeks of age. During this period, the birds were fed on a commercial standard grower diet. The pens were placed in open sided houses with cement floor on a $15 \mathrm{~cm}$ deep wood shaving litter. Each pen was $230 \mathrm{~cm}$ long, $143 \mathrm{~cm}$ wide and $120 \mathrm{~cm}$ high. An experimental unit, represented by a pen, contained six randomly selected birds of the same sex. Eight pens were randomly assigned for each diet, four pens for male birds and four pens for the female birds. A minimum of $15 \mathrm{~h}$ light was provided daily throughout the experimental period. No antibiotic or growth promotant was administered. Water and feed were given ad libitum. Water was provided in $4 \mathrm{~L}$ plastic founts and the feed was given in $10 \mathrm{~L}$ plastic hanging feeders. The wood shavings were changed fortnightly or whenever there was water spillage. At 13 weeks at age, the birds were introduced to the experimental dietary treatments. The initial average individual weights of the male and female birds at 13 weeks were $1.6 \pm 0.33$ and $1.2 \pm 0.42 \mathrm{~kg}$ respectively.

Two dietary treatments were used. The control diet was formulated with $100 \%$ white maize (WM) and the PABM-based diet was formulated with $100 \%$ HP326-6 maize variety (Table 1). The PABM maize was obtained from Makhathini Research Station, Jozini, KwaZulu-Natal where it was planted. The aim of biofortification of maize with provitamin A carotenoids was to increase the concentration of $\beta$-carotene in the endosperm of the maize.

Table 1 - Feed composition of experimental diets.

\begin{tabular}{lcc}
\hline Ingredients & (Control-WM) $\mathrm{kg}$ & PABM(kg) \\
\hline Provitamin A biofortified maize & 0.0 & 417.7 \\
White maize & 417.7 & 0 \\
Soya meal & 175.4 & 175.4 \\
Vegetable oil & 23.8 & 23.8 \\
Limestone & 12.3 & 12.3 \\
Declaim phosphate & 6.9 & 6.9 \\
Salt & 1.9 & 1.9 \\
DL-Methionine & 1.2 & 1.2 \\
L-Lysine & 0.1 & 0.1 \\
Vit.-min. premix (excluding vit A) & 3.2 & 3.2 \\
\hline Nutrient composition & & \\
\hline Metabolizable energy (MJ/kg) & 12.56 & 13.01 \\
Crude protein (g/kg) & 199 & 198 \\
Ash (g/kg) & 110 & 97.3 \\
Calcium (g/kg) & 10 & 11 \\
Phosphorus (g/kg) & 7.4 & 8.1 \\
Provitamin A carotenoids(mg/kg) & 0.1 & 0.5 \\
\hline
\end{tabular}

One $\mathrm{kg}$ of feed contained the following:; cholecalciferol,60 mg; all-rac-_ tocopheryl acetate, $30 \mathrm{mg}$; menadione, $3 \mathrm{mg}$; thiamine, $22 \mathrm{mg}$; riboflavin, $8 \mathrm{mg}$; pyridoxine, $5 \mathrm{mg}$; cyanocobalamin, $11 \mathrm{mg}$; folic acid, 1.5mg; biotin, $150 \mathrm{mg}$; calcium pantothenate, 25 mg; nicotinic acid, 65 mg; Mn, 60 mg; Zn, 40 mg; I, 0.33 mg; Fe, 80 mg; Cu, 8 mg; Se, $0.15 \mathrm{mg}$; ethoxyquin, 150

\section{Feed Analysis}

The fat content of WM and PABM dry milled maize flour was determined using Soxhlet extraction method (AOAC, 1984). To determine the crude protein, the total nitrogen content was determined by Kjeldahl nitrogen analysis according to AOAC (1995). The percentage ash content was calculated as: $\%$ ash = weight of ash $x$ 100/ weight of sample (AOAC, 1980). The gross energy values were estimated by multiplying the crude protein, fat and carbohydrate by their water values. Calcium and phosphorus were determined by atomic absorption spectrophotometer method and colorimetrically respectively according to AOAC (1984). Carotenoid analysis was carried out using a Hewlett Packard 1100 HPLC (Agilent Technologies Incorporated, Loveland, CO, USA) consisting of a binary pump, autosampler, column thermostat, diode array detector and ChemStation software (Revision B.03 02, Agilent Technologies Incorporated, Loveland, (O, USA).

\section{Data collection}

At 18 and 21 weeks ( 5 and 8 weeks of feeding on experimental diets), 16 birds from each dietary treatment, that is, eight female and eight male birds, two birds from each replicate were randomly selected, totalling 32 birds (16 female and 16 male birds) from 
Odunitan-Wayas F, Kolanisi U, Chimonyo M
Haematological and Serum Biochemical Responses of Ovambo Chickens Fed Provitamin A Biofortified Maize both dietary treatment. From each of the selected birds, two sets of blood samples were collected via the jugular vein. One set of blood samples was collected into $5 \mathrm{ml}$ purple top vacutainer tubes containing an anticoagulant, ethylene diaminetetra-acetic acid (EDTA) for determining the haematological parameters. The other set of blood samples was collected into $5 \mathrm{ml}$ vacutainer tubes that did not contain any anticoagulant. The coagulated blood samples were centrifuged for 15 minutes at $3000 \mathrm{rpm}$ to collect the serum before they were stored at $-20^{\circ} \mathrm{C}$ pending analyses.

\section{Haematological parameters}

The packed cell volume (PCV) was measured by a microhaematocrit capillary tube using a Hemocrit reader. Erythrocyte concentration (RBC), haemoglobin $(\mathrm{Hb})$ and leucocytes concentration (WBC) counts were measured using an automated cell counter within 24 hours after collection of blood. The mean corpuscular volume (MCV), mean corpuscular haemoglobin (MCH) and mean corpuscular haemoglobin concentration (MCHC) were also calculated (Jain, 1986). The formulae used were:

MCV in femrolitres $(\mathrm{fL})=10 \times \mathrm{PCV}(\%) / \mathrm{RBC}$ counts (millions/ $/$ l).

$\mathrm{MCH}$ in pg/cell= haemoglobin $(\mathrm{g} / 100 \mathrm{ml}) / \mathrm{RBC}$ counts (millions $/ \mu \mathrm{l})$. (\%)

MCHC in $\mathrm{g} / \mathrm{dl}=$ haemoglobin $(\mathrm{g} / 100 \mathrm{ml}) \times 100 / \mathrm{PCV}$

\section{Biochemical parameters}

The albumin, serum lipid profile, total protein, uric acid, creatinine and activities of the liver enzymes, alanine transaminase, aspartate transaminase and alkaline phosphatase were measured at the School of Biochemistry, Genetics and Microbiology, University of KwaZulu-Natal, Westville Campus, Durban, South Africa using an automated chemistry analyser (LabmasPlenno, Labtest, Lagoa-Santa Brazil). Globulin was calculated as the difference between total proteins and albumin.

\section{Statistical Analyses}

The data were analyzed using the PROC MIXED of SAS (Statistical Analysis System, version 9.2) with tests of means (PROC LSMEANS) for significant variables. The model used included diet, age and sex as fixed variables. Statistical significance was considered at the $5 \%$ level of probability.

The model used was: $Y_{i j k l}=\mu+D_{i}+S_{i}+A_{k+}(D \times S)_{i j}$ $+(D \times A)_{i k}+(D \times S \times A)_{i j k+} E_{i j k l}$
Where: $Y_{i j k l=}$ response variable (haematological and serum biochemistry parameters)

$\mu=$ the overall mean

$D_{i}=$ effect of the $i^{\text {th }}$ diet with $i=$ PABM and WM diet;

$S_{i}=$ effect of the $j^{\text {th }}$ sex with $j=$ male and female birds

$A_{k}=$ effect of the $k^{\text {th }}$ age with $k=18$ and 21 weeks;

$(D \times S)_{i j}=$ interaction of the $i^{\text {th }}$ diet and the $j^{\text {th }}$ sex;

$(D \times A)_{i k=}$ interaction of the $i^{\text {th }}$ diet and the $k^{\text {th }}$ age of bird;

$(D \times S \times A)_{i j k}=$ interaction of the $i^{\text {th }}$ diet, $j^{\text {th }}$ sex of bird and the $k^{\text {th }}$ age of bird;

$\mathrm{E}_{\mathrm{i} k \mathrm{k}}=$ random error term assumed to be normally and independently distributed with mean 0 and variance equal to $ð^{2}$.

\section{RESULTS}

\section{Effect of diet, sex and age on haemato- logical parameters of Ovambo chickens}

The effects of diet, sex and age on haematological parameters of Ovambo chickens are reported in Table 2. Female birds fed on the PABM diet had a significantly higher RBC than the female birds fed on the WM diet. The male birds had higher PCV than the female birds, but it was only significant in the WM fed birds. The PABM fed birds had significantly higher WBC than the WM fed birds. The WBC of the female birds was higher than the male birds. At 21 weeks of age, the PABM fed females had a lower MCV than the WM fed female birds, while the PABM fed male birds had a higher MCV than the WM fed male birds. At 18 weeks of age, the PABM fed female birds had a lower MCH than the WM fed female birds. The PABM fed birds at 21 weeks of age had higher MCHC then the PABM fed birds at 18 weeks of age. The PABM fed male birds at 21 weeks of age had higher MCHC than the WM fed birds at 21 weeks of age (Table 2).

\section{Effect of diet, sex and age on serum biochemistry of Ovambo chickens}

The effects of the diet, sex and age on serum biochemistry of Ovambo chickens are shown in Table 3. The PABM fed male birds at 21 weeks of age had a significantly higher ALB than the WM fed male birds of the same age. The male birds had higher ALB than the female birds, but it was only significant in the WM fed male birds and female birds at 18 weeks. At 18 weeks of age, the ALP of the PABM fed male birds was lower $(p<0.05)$ than the WM fed male birds (Table 3 ). The WM fed female had a higher AST than the PABM 
Table 2 - Effect of diet, sex and age of bird on the haematological parameters of Ovambo chickens.

\begin{tabular}{|c|c|c|c|c|c|c|c|c|c|}
\hline & \multicolumn{4}{|c|}{18 weeks } & \multicolumn{4}{|c|}{21 weeks } & \multirow[b]{3}{*}{ SEM } \\
\hline & \multicolumn{2}{|c|}{ WM } & \multicolumn{2}{|c|}{ PABM } & \multicolumn{2}{|c|}{ WM } & \multicolumn{2}{|c|}{ PABM } & \\
\hline & Male & Female & Male & Female & Male & Female & Male & Female & \\
\hline RBC $(x 106 \mu)$ & $2.79^{a b}$ & $2.57^{b}$ & $2.85^{\mathrm{ab}}$ & $2.88^{a}$ & $2.84^{\mathrm{ab}}$ & $2.45^{b}$ & $2.77^{\mathrm{ab}}$ & $2.86^{a}$ & 0.11 \\
\hline $\mathrm{Hb}(\mathrm{g} / \mathrm{dl})$ & $11.28^{b}$ & $10.16^{a}$ & $11.45^{b}$ & $10.80^{\mathrm{ab}}$ & $11.00^{\mathrm{ab}}$ & $10.23^{a}$ & $11.48^{b}$ & $11.01^{\mathrm{ab}}$ & 0.36 \\
\hline PCV (\%) & $38.00^{a}$ & $33.75^{b}$ & $38.25^{\mathrm{a}}$ & $36.50^{\mathrm{ab}}$ & $38.20^{\mathrm{a}}$ & $34.34^{b}$ & $37.67^{a}$ & $35.94^{\mathrm{ab}}$ & 1.07 \\
\hline WBC (g/dl) & $15.95^{\mathrm{a}}$ & $20.65^{b}$ & $23.20^{\mathrm{bc}}$ & $26.20^{c}$ & $15.15^{a}$ & $20.50^{b}$ & $22.16^{\mathrm{bc}}$ & $23.45^{b c}$ & 1.29 \\
\hline $\mathrm{MCV}(\mathrm{fL})$ & $136.50^{b}$ & $131.61^{\mathrm{ab}}$ & $134.96^{b}$ & $127.41^{\mathrm{a}}$ & $131.20^{b}$ & $133.02^{\mathrm{ab}}$ & $135.99^{b}$ & $125.66^{a}$ & 2.17 \\
\hline MCH ( pg/cell) & $40.43^{b}$ & $39.61^{b}$ & $40.37^{b}$ & $29.64^{a}$ & $39.21^{b}$ & $40.18^{b}$ & $41.44^{b}$ & $38.50^{b}$ & 0.57 \\
\hline $\mathrm{MCHC}(\mathrm{g} / \mathrm{dl})$ & $29.64^{a}$ & $30.11^{\mathrm{a}}$ & $29.94^{\mathrm{a}}$ & $29.58^{a}$ & $29.10^{a}$ & $30.00^{a}$ & $30.48^{b}$ & $30.63 a$ & 0.29 \\
\hline
\end{tabular}

Superscript letters indicate differences $(p<0.05)$ in rows.

WM: white maize (control), PABM: provitamin A biofortified maize, RBC: red blood cell, Hb: haemoglobin, PCV: packed cell volume; WBC: white blood cell, MCV: mean corpuscular volume, MCH: mean corpuscular haemoglobin, MCHC: mean corpuscular haemoglobin concentration. SEM: standard error of mean.

female at 21 weeks of age. The PABM fed female birds had a higher ALT than the WM fed female birds at 21 weeks of age. White maize fed male birds had a significantly higher ALT than the PABM fed male birds at 18 weeks of age (Table 3 ).

Cholesterol concentrations in the WM fed male birds were higher than the PABM male fed birds at 18 and 21 weeks of age, however it was only significant between the male birds at 18 weeks of age. The WM fed male birds at 21 weeks of age had a significantly lower creatinine concentration than the WM fed females of the same age. The female birds at 21 weeks of age had higher TP than the male birds of the same age. The PABM fed females at 21 weeks of age had higher $(p<0.05)$ globulin than the WM fed females of the same age. The female birds at 21 weeks of age had a significantly higher $(p<0.05)$ globulin amount than male birds of the same age (Table3). The triglycerides of the female birds regardless of the diet and age were higher than the male birds; however, it was only significant between the female and male birds at 21 weeks of age. The triglycerides of the female birds at 21 weeks of age were also significantly higher than the female birds at 18 weeks of age. The PABM fed male birds at 21 weeks of age had a significantly lower uric acid concentration than the PABM fed female birds and the WM male birds of the same age (Table 3).

Table 3 - Effect of diet, sex and age of bird on the serum biochemistry of Ovambo chickens

\begin{tabular}{|c|c|c|c|c|c|c|c|c|c|}
\hline & \multicolumn{4}{|c|}{18 weeks } & \multicolumn{4}{|c|}{21 weeks } & \multirow[b]{3}{*}{ SEM } \\
\hline & \multicolumn{2}{|c|}{ WM } & \multicolumn{2}{|c|}{ PABM } & \multicolumn{2}{|c|}{ WM } & \multicolumn{2}{|c|}{ PABM } & \\
\hline & Male & Female & Male & Female & Male & Female & Male & Female & \\
\hline ALB (mg/dl) & $2.08^{b c}$ & $2.12^{\mathrm{bc}}$ & $2.06^{b c}$ & $2.17^{\mathrm{bc}}$ & $1.50^{\mathrm{a}}$ & $2.36^{c}$ & $1.97^{b}$ & $2.15^{b c}$ & 0.11 \\
\hline ALP (U/L) & $986.50^{c}$ & $703.75^{a b}$ & $558.50^{\mathrm{a}}$ & $647.00^{\mathrm{ab}}$ & $686.00^{\mathrm{ab}}$ & $791.00^{\mathrm{bc}}$ & $714.25^{\mathrm{ab}}$ & $713.50^{\mathrm{ab}}$ & 76.43 \\
\hline ALT (U/L) & $6.25^{\text {abd }}$ & $3.00^{\mathrm{ac}}$ & $1.13^{c}$ & $4.25^{\mathrm{ac}}$ & $3.50^{\text {ace }}$ & $4.50^{\text {ad }}$ & $6.50^{\text {de }}$ & $8.75^{\text {bd }}$ & 1.19 \\
\hline AST (U/L) & $276.38^{a}$ & $241.88^{a}$ & $325.00^{a}$ & $276.13^{\mathrm{a}}$ & $263.75^{a}$ & $855.00^{b}$ & $279.50^{\mathrm{a}}$ & $240.25^{a}$ & 146.26 \\
\hline CHOLES (mg/dl) & $230.63^{d}$ & $113.63^{\mathrm{ac}}$ & $115.50^{\mathrm{ac}}$ & $106.25^{\mathrm{ac}}$ & $119.25^{a c}$ & $141.50^{\mathrm{ac}}$ & $100.75^{a}$ & $129.00^{a c}$ & 46.08 \\
\hline $\mathrm{CREAT}(\mathrm{ml})$ & $1.69^{\mathrm{ab}}$ & $0.62^{\mathrm{a}}$ & $1.40^{\mathrm{a}}$ & $0.77^{a}$ & $1.02^{\mathrm{a}}$ & $5.54^{\mathrm{b}}$ & $1.00^{\mathrm{a}}$ & $3.43^{\mathrm{ab}}$ & 1.42 \\
\hline TP $(g / d l)$ & $4.14^{b}$ & $4.17^{b}$ & $4.10^{b}$ & $4.24^{b}$ & $3.55^{\mathrm{a}}$ & $4.85^{c}$ & $4.00^{\mathrm{ab}}$ & $5.22^{c}$ & 0.17 \\
\hline TRI (mg/dl) & $66.25^{a}$ & $96.63^{a}$ & $65.75^{a}$ & $81.88^{a}$ & $56.25^{a}$ & $512.25^{c}$ & $51.75^{a}$ & $441.50^{c}$ & 120.97 \\
\hline Uric acid (mg/dl) & $10.92^{\mathrm{a}}$ & $10.94^{a}$ & $9.17^{a}$ & $10.71^{\mathrm{a}}$ & $8.29^{a}$ & $8.96^{a}$ & $5.26^{b}$ & $9.06^{a}$ & 0.96 \\
\hline Globulin & $2.06^{\mathrm{a}}$ & $2.04^{\mathrm{a}}$ & $2.04^{\mathrm{a}}$ & $2.06^{\mathrm{a}}$ & $2.05^{\mathrm{a}}$ & $2.49^{c}$ & $2.03^{\mathrm{a}}$ & $3.06^{b}$ & 0.10 \\
\hline
\end{tabular}

Values with different superscripts in the same row differ $(p<0.05)$. WM: white maize, PABM: provitamin A biofortified maize, ALB: albumin, ALP: alkaline phosphate, ALT: alanine transaminase, AST: aspartate transaminase, CHO: cholesterol, CREAT: Creatinine TP: total protein, TRI: triglycerides.

\section{DISCUSSION}

The normal ranges of the haematological parameters in chickens are RBC: 2.5-3.5 x10 $\mu$, PCV: $22-35 \%, \mathrm{Hb}: 7-13 \mathrm{~g} / \mathrm{dl}$ and WBC: $12-30 \times 10^{3}$ $\mu \mathrm{l}$ (Bounous \& Stedman, 2000). The MCV is used to calculate the average erythrocyte size, the $\mathrm{MCH}$ to measure haemoglobin amount per blood cell and the
MCHC to know the amount of haemoglobin relative to the size of the cell per red blood cell. Their normal ranges are $\mathrm{MCV}$ : $90-140 \mathrm{fL}, \mathrm{MCH}$ : 33-47 pg/cell and MCHC: $26-35 \mathrm{~g} / \mathrm{dl}$ (Bounous \& Stedman, 2000). All the values obtained for the haematological parameters in this study were within their normal range.

The function of RBC is to transport oxygen from the lungs to tissues and remove carbon dioxide from 
the tissues to the lung in the body via haemoglobin. The RBC range of chickens is affected by sex and diet of birds (Kaminski et al., 2014). The findings in the current study indicate that the effect of PABM on RBC is more evident in female birds is comparable with earlier study (Kaminski et al., 2014). The RBC and $\mathrm{Hb}$ concentrations are influenced by reproductive hormones. The significantly higher PCV of the male birds fed WM diet than the WM fed female birds is supported by earlier findings on indigenous chickens (Elagib \& Ahmed, 2011; Sharmin \& Myenuddin, 2004). The higher amount of $\mathrm{Hb}$ and MCV in the male birds could be because of the androgen hormone present in the male birds, as increased level of PCV in male birds correspond with the time of androgen production (Adedibu et al., 2014; Cecil \& Bakst, 1991). The increase in PCV can be used to envisage sexual maturity and the start of semen production. It would seem that the PABM reduced the effect of sex on PCV as the PCV of the PABM male and female birds was not significant. In general, haematological parameters of indigenous birds are influenced by several factors that include the sex and diet (Elagib \& Ahmed, 2011).

The WBC aids to protect the body from pathogen and carotenoids build up immunity (Osman et al., 2004; Saladin, 2003). The PABM diet increased the WBC of the birds in the current study. This is similar to earlier report that supplementation of vitamin $A$ increases WBC concentration in chickens (Akbari et al., 2008). Other reports also indicate that vitamin $A$ and carotenoids increase the immune response in chickens and also reduce common avian infections such as coccidiosis and lesions that cause significant losses to poultry farmers (Díaz-Gómez et al., 2015; Sepehri Moghaddam \& Emadi, 2014). Carotenoids have been documented to have antioxidant activities that reduces stress and help the birds to fight infections better (Nogareda et al., 2016). Higher level of WBC in female birds than the male birds is similar to earlier findings (Addass et al., 2012; Cucco et al., 2007; Sharmin \& Myenuddin, 2004). Lower WBC in male birds could be due to the presence of testosterone in the male's plasma which could suppress immune response (Müller et al., 2003). In the current study, it is evident that the PABM diet boosted immune response.

Total protein is made up of ALB and globulin. Globulin is calculated as the difference between TP and ALB. The normal ranges of the TP and ALB in bird's blood are 3.0-4.9 mg/dl and 1.17-2.74 g/dl, respectively (Meluzzi et al., 1992). All the birds regardless of their diet, age at slaughter and sex were within the normal range of
TP and ALB. Albumin, a serum protein is synthesized in the liver. It is responsible for transporting insoluble substance in the blood and aids to maintain oncontic pressure (Fischbach \& Dunning, 2009). A higher concentration of ALB usually denotes dehydration while a lower concentration may be due to the liver not functioning adequately due to factors such as malnutrition and infection (Esubonteng, 2011). Total proteins in the female birds were higher than the male birds. This could be attributed to oestrogen induced increase in globulin in preparation of the female bird's body for egg laying (Simaraks et al., 2004).

Liver enzymes, namely the alanine transaminase albumin (ALT), alkaline phosphatase (ALP) and aspartate transaminase (AST) are important in the determination of the proper functioning of the liver (Ambrosy et al., 2015). These enzymes are present in negligible concentration. An increase in the concentration of these enzymes may be because of damaged or diseased cells which denote the status of the liver function. The high concentration of AST in the WM fed female birds at 21 weeks of age could be an indication of damage to the liver. The normal range of the concentration of liver enzymes are: AST:70-220 U/L, ALP: 568-8831 U/L (Meluzzi et al., 1992). Vitamin A deficiency increases the levels of AST and ALT (Roodenburg et al., 1996).

Creatinine is used to determine the status of the kidney. The functions of the kidney include excretion of waste products resulting from protein metabolism and muscle contraction (lleke et al., 2014). Creatinine is excreted by the kidney as a by-product of creatinephosphate metabolism which is produced as a result of energy production by the skeletal muscles (Esubonteng, 2011). The high level of creatinine in the female birds at 21 weeks can be attributed to the metabolic changes as a result of sexual maturity (Menon et al., 2013). A high amount of creatinine could also indicate that the kidney is not functioning optimally thus, the high level in the WM fed female birds at 21 weeks of age compared to the PABM fed females indicates a lower than optimal functioning of the kidney. Vitamin A and its active metabolites have been reported to affect the development of kidney which is associated with the proper functioning of kidney resulting in the high level of creatinine (Gilbert, 2002).

High protein intake, increased protein metabolism, stress and dehydration influence the concentration of uric acid in the blood as it is produced as a result of protein metabolism (Chernecky \& Berger, 2008). The normal range of uric acid is $1.9-12.5 \mathrm{mg} / \mathrm{dl}$ (Clinical 
diagnostic division, 1990). Age, sex and diet of birds influence the amount of uric acid. A high level of uric acid (hyperuricemia) is usually evident in female birds due to ovulatory activities (Ibrahim et al., 2012). The amount of uric acid in female birds was higher than the male birds at both stages of slaughter; however, it was only significant at 21 weeks of age in the PABM fed birds. This can be attributed to the fact that, at 18 weeks of age, the female birds have not started laying eggs. The average maturity age for egg laying is 21 weeks (Van Marle-Koster \& Nel, 2000).

The concentration of cholesterol of the WM fed male birds at 18 weeks was above the normal range,87-192 $\mathrm{mg} / \mathrm{m}$ (Meluzzi et al., 1992) of cholesterol in birds. Cholesterol is synthesized from fats consumed and endogenously synthesized within the cells. A high level of cholesterol is an indication of a high risk to cardiovascular disease. The findings of the current study agrees with reports that $\beta$ - carotene diet reduces serum cholesterol (e Silva et al., 2013). Other earlier report agree with the finding of this study that carotenoids diet reduces total cholesterol in chickens (Rao \& Shen, 2002). Furthermore, the absence or presence of cholesterolaemic effects of dietary components in an animal depends on various factors such as breed, sex and age, and also on the composition of the feed (Toghyani et al., 2010).

Triglycerides (TRI) are synthesized in the liver from fatty acids, and from protein and glucose when they are above the body's current needs and then stored in adipose tissue (Esubonteng, 2011). The TRI of the WM fed female birds at 21 weeks of age was above the normal range (45.7-172) $\mathrm{mg} / \mathrm{ml}$ (Meluzzi et al., 1992) and higher than the PABM fed female birds and the male birds Serum biochemical constituents are positively correlated with the quality of the diet (Adeyemi et al., 2000; Etuk et al., 2014).

\section{CONCLUSIONS}

The use of PABM as a major feed ingredient and source of vitamin A for female and male Ovambo chickens within the ages of 13 to 21 weeks will positively impact on the health status of the Ovambo chicken. The sex of the birds is a contributory factor to the impact of the PABM on the haematological parameters. The PABM improved the immune response of the birds, especially in the female birds and the cholesterol levels of the birds. These will consequently improve the general performance of Ovambo chickens. Consequently, white maize commonly fed to Ovambo chickens in southern Africa can be replaced with PABM without any detrimental effects to the well-being of the chickens. Consumption of the PABM diet will result in healthier Ovambo chickens with better resistance to avian diseases and infections that cause significant economic losses to the poultry farmers. Commercial poultry farmers could also adopt the use of PABM diet to reduce cost in terms of purchasing vitamin $A$ supplementation, medications and vaccines to combat infections.

\section{ACKNOWLEDGEMENTS}

The authors thank the Centre for Indigenous Knowledge System, University of KwaZulu-Natal for providing a bursary, Cedara College of Agriculture for housing the chickens and Makhathini Research Station for growing the biofortified maize used in the study.

\section{REFERENCES}

Addass P, David D, Edward A, Zira K, Midau A. Effect of age, sex and management syste on some haematological parameters of intensively and semi-intensively kept chicken in Mubi, Adamawa State, Nigeria. Iranian Journal of Applied Animal Science 2012;2(3):277-282.

Adedibu I, Ayorinde K, Musa A. identification of hematological markers suitable for improving productivity of helmeted guinea fowl numida meleagris. American Journal of Experimental Agriculture 2014;4(10):1186.

Adeyemi O, Fasina O, Balogun M. Utilization of full fat jatropha seeds in broiler diet: effect on haematological parameters and blood chemistry. Proceedings of the 25th Conference of Nigerian Society for Animal Production; 2000; Umudike: Michael Okpara University of Agriculture; 2000. p. 19-23.

Aganga A, Tshwenyane S, Molefhe L. Influence of feed type on egg production of tswana laying chicken. International Journal of Poultry Science 2003;2(4):256-258.

Akbari M, Kermanshahi $\mathrm{H}$, Moghaddam HN, Moussavi AH, Afshari JT. Effects of wheat-soybean meal based diet supplementation with vitamin a, vitamin e and zinc on blood cells, organ weights and humoral immune response in broiler chickens. Journal of Animal and Veterinary Advances 2008;7(3):297-304.

Aluru M, Xu Y, Guo R, Wang Z, Li S, White W, et al. Generation of transgenic maize with enhanced provitamin a content. Journal of Experimental Botany 2008;59(13):3551-3562.

Ambrosy AP, Dunn TP, Heidenreich PA. Effect of minor liver function test abnormalities and values within the normal range on survival in heart failure. The American Journal of Cardiology 2015;115(7):938-941.

AOAC - Association of Official Analytical Chemistry. Official methods of analysis of AOAC International. 16 $6^{\text {th }}$ ed. Arlington; 1995.

AOAC - Association of Official Analytical Chemistry. Official methods of analysis of AOAC International. 14 ${ }^{\text {th }}$ ed. Arlington; 1984.

AOAC - Association of Official Analytical Chemistry. Official methods of analysis of AOAC International. 13 th ed. Washington; 1980. 
Bárdos L, Jung I, Kerti A, Szabo C, Kiss Z, Lakner H. Carotenoids and body defense in accordance with experiences on poultry. Risk Factors and Biological Systems 2011;1:114-124.

Bounous D, Stedman N. Normal avian hematology: chicken and turkey. In: Feldman BF, Zinkl JG, Jain NC, editors. Schalm's veterinary hematology. New York: Wiley; 2000. p.1147-1154.

Cecil HC, Bakst MR. Correlations of organ weights, hematocrit, and testosterone with sexual maturity of the male turkey. Poultry Science 1991;70(5):1252-1257.

Chernecky C, Berger B. Laboratory tests and diagnostic procedures. St Louis: Saunder Elsevier; 2008.

Chumngoen W, Tan FJ. Relationships between descriptive sensory attributes and physicochemical analysis of broiler and taiwan native chicken breast meat. Asian-Australasian Journal of Animal Sciences 2015;28(7):1028.

Clinical diagnostic division. Veterinary reference guide. Rochester: Eastman Kodak Company; 1990.

Cucco M, Guasco B, Malacarne G, Ottonelli R. Effects of B-Carotene on adult immune condition and antibacterial activity in the eggs of the grey partridge, perdix perdix. Comparative Biochemistry and Physiology Part A: Molecular \& Integrative Physiology 2007;147(4):1038-1046.

Desta TT, Wakeyo O. Village chickens management in wolaita zone of southern Ethiopia. Tropical Animal Health and Production 2013;45(2):387-396.

Díaz-Gómez J, Moreno Martínez JA, Angulo Asensio E, Sandmann G, Portero Otín M, Capell Capell T, et al. Carotenoid-enriched transgenid corn in poultry nutrition. ISB News Report 2015; 8-11.

Santos Schmidt EM, Paulillo AC, Martins GRV, Lapera IM, Testi AJP, Junior LN, et al. Hematology of the bronze turkey (meleagris gallopavo): variations with age and gender. International Journal of Poultry Science 2009;8(8):752-754.

Silva LS, Miranda AM, Brito Magalhães $C L$, Santos RC, Pedrosa ML, Silva ME. Diet supplementation with beta-carotene improves the serum lipid profile in rats fed a cholesterol-enriched diet. Journal of Physiology and Biochemistry 2013;69(4):811-820.

Elagib H, Ahmed A. Comparative Study on haematological values of blood of indigenous chickens in Sudan. Asian Journal of Poultry Science 2011;5(1):41-45.

Esubonteng PKA. An assessment of the effect of moringa olifera leaf powder as a nutritional supplement in the diet. Kumasi: Kwame Nkrumah University of Science and Technology; 2011

Etuk E, Ugwu C, Inyama E, Ugorji C. Blood chemistry, haematology, carcass characteristics and organ weight of finisher broilers fed breadfruit (Treculia Africana) hull (Bfh) in their diet. Comparative Clinical Pathology 2014;23(5):1153-1158.

Fischbach FT, Dunning MB. A manual of laboratory and diagnostic tests. Philadelphia: Lippincott Williams \& Wilkins; 2009.

Gilbert T. Vitamin a and kidney development. Nephrology Dialysis Transplantation 2002;17(suppl 9):78-80.

Huff G, Huff W, Rath N, Anthony N, Nestor K. Effects of Escherichia coli challenge and transport stress on hematology and serum chemistry values of three genetic lines of turkeys. Poultry Science 2008;87(11):2234-2241.

Ibrahim A, Aliyu J, Abdu M, Hassan A. Effects of age and sex on serum biochemistry values of turkeys (Meleagris gallopavo) reared in the semi-arid environment of Nigeria. World Applied Sciences Journal 2012;16(3):433-436. lleke KD, Odeyemi OO, Ashamo MO, Oboh G. Toxicological and histopathological effects of cheese wood, alstonia boonei de wild stem bark powder used as cowpea protectant against cowpea bruchid, callosobruchus maculatu (fab.)[coleoptera: chrysomelidae] on albino rats. Ife Journal of Science 2014;16(1):23-33.

Jain NC. Schalm's veterinary hematology. Philadelphia: Lea \& Febiger; 1986.

Kaminski $P$, Jerzak L, Sparks TH, Johnston A, Bochenski M, Kasprzak $M$, et al. Sex and other sources of variation in the haematological parameters of white stork ciconia ciconia chicks. Journal of Ornithology 2014;155(1):307-314

Kennedy OB, Stewart-Knox BJ, Mitchell PC, Thurnham DI. Flesh colour dominates consumer preference for chicken. Appetite 2005;44(2):181186.

Liu S, Hao Z, Weng J, Li M, Zhang D, Pan G, et al. Identification of two functional markers associated with drought resistance in maize. Molecular Breeding 2015;35(1):1-10.

Magala $H$, Kugonza D, Kwizera H, Kyarisiima C. Influence of management system on growth and carcass characteristics of ugandan local chickens. Journal of Animal Science Advances 2012;2(6):557-567.

Meluzzi A, Primiceri G, Giordani R, Fabris G. Determination of blood constituents reference values in broilers. Poultry Science 1992;71(2):337-345.

Menon D, Bennett D, Schaefer A, Cheng K. Hematological and Serum biochemical profile of farm emus (Dromaius novaehollandiae) at the onset of their breeding season. Poultry Science 2013;92(4):935-944.

Müller W, Dijkstra C, Groothuis TG. Inter-sexual differences in t-cellmediated immunity of black-headed gull chicks (Larus ridibundus) depend on the hatching order. Behavioral Ecology and Sociobiology 2003;55(1):80-86

Nogareda C, Moreno JA, Angulo E, Sandmann G, Portero M, Capell T,et al. Carotenoid-enriched transgenic corn delivers bioavailable carotenoids to poultry and protects them against coccidiosis. Plant Biotechnology Journal 2016;14(1):160-168.

Odunitan-Wayas F, Kolanisi U, Chimonyo M, Siwela M. Effect of provitamin a biofortified maize inclusion on quality of meat from indigenous chickens. The Journal of Applied Poultry Research 2016;25(4):581-590.

Osman ZM, Gomaa AM, Hussein HM, Soliman FH, El-Shobaki AF. Association between retinol metabolism and diabetic retinopathy. Polish Journal of Food and Nutrition 2004;13:54.

Penniston KL, Tanumihardjo SA. The acute and chronic toxic effects of vitamin A. The American Journal of Clinical Nutrition 2006;83(2):191201.

Pillay K, Derera J, Siwela M, Veldman FJ. Consumer acceptance of yellow, provitamin a-biofortified maize in Kwazulu-Natal: original research. South African Journal of Clinical Nutrition 2011;24(4):186-191.

Pixley K, Rojas NP, Babu R, Mutale R, Surles R, Simpungwe E. Biofortification of maize with provitamin a carotenoids. In: Tanumihardjo AS, editor. Carotenoids and human health. Totowa: Humana Press; 2013. p 271292.

Rao A, Shen $\mathrm{H}$. Effect of low dose lycopene intake on lycopene bioavailability and oxidative stress. Nutrition Research 2002;22(10):1125-1131.

Roodenburg AC, West CE, Hovenierl R, Beynen AC. Supplemental vitamin a enhances the recovery from iron deficiency in rats with chronic vitamin a deficiency. British Journal of Nutrition 1996;75(04):623-636.

Saladin K. The Male reproductive system. Anatomy and physiology: the unit of form and function. New York: McGraw- Hill; 2003. p.1017-1047. 
Sepehri Moghaddam $\mathrm{H}$, Emadi M. The effect of threonine and vitamin a on immune system in broiler chickens. International Journal of Advanced Biological and Biomedical Research 2014;2(3):756-763.

Sharma SL, Singh P, Patil AK, Sharma J. Effect of feeding compressed complete feed block containing guar meal on blood biochemical profile of crossbred calves. Journal of Animal Research 2015;5(3):575.

Sharmin M, Myenuddin M. Hematological values of the indigenous chickens. Bangladesh Journal of Veterinary Medicine 2004;2(2):163164.

Simaraks S, Chinrasri O, Aengwanich W. Hematological, electrolyte and serum biochemical values of the thai indigenous chickens (Gallus domesticus) in Northeastern, Thailand. Songklanakarin Journal of Science and Technology 2004;26(3):425-430.

Smale M, Byerlee D, Jayne T. Maize revolutions in sub-saharan Africa. An African green revolution. Berlim: Springer; 2013. p 165-195.

Summers J. Maize: factors affecting its digestibility and variability in its feeding value. In: Bedford MR, Partridge GG, editors. Enzymes in farm animal nutrition. Wallingford: Cabi; 2001. p. 109-124.
Toghyani M, Toghyani M, Gheisari A, Ghalamkari G, Mohammadrezaei M. Growth performance, serum biochemistry and blood hematology of broiler chicks fed different levels of black seed (Nigellasativa) and peppermint (Mentha piperita). Livestock Science 2010;129(1):173-178.

Van Marle-Köster E, Casey N. Phenotypic characterisation of native chicken lines in South Africa. Animal Genetic Resources Information 2001;29:71-78.

Van Marle-Koster E, Nel L. Genetic characterization of native southern african chicken populations: evaluation and selection of polymorphic microsatellite markers. South African Journal of Animal Science 2000;30(1):1-6

Van Marle-Koster E, Webb E. Carcass characteristics of south african native chicken lines. South African Journal of Animal Science 2000;30(1):5356.

Yang $Y$, lji $\mathrm{P}$, Choct $\mathrm{M}$. Dietary modulation of gut microflora in broiler chickens: a review of the role of six kinds of alternatives to in-feed antibiotics. World's Poultry Science Journal 2009;65(1):97-114. 
